NASA/TM-2004-213063

\title{
Probabilistic Aeroelastic Analysis of Turbomachinery Components
}

T.S.R. Reddy and S.K. Mital

University of Toledo, Toledo, Ohio

G.L. Stefko

Glenn Research Center, Cleveland, Ohio 
Since its founding, NASA has been dedicated to the advancement of aeronautics and space science. The NASA Scientific and Technical Information (STI) Program Office plays a key part in helping NASA maintain this important role.

The NASA STI Program Office is operated by Langley Research Center, the Lead Center for NASA's scientific and technical information. The NASA STI Program Office provides access to the NASA STI Database, the largest collection of aeronautical and space science STI in the world. The Program Office is also NASA's institutional mechanism for disseminating the results of its research and development activities. These results are published by NASA in the NASA STI Report Series, which includes the following report types:

- $\quad$ TECHNICAL PUBLICATION. Reports of completed research or a major significant phase of research that present the results of NASA programs and include extensive data or theoretical analysis. Includes compilations of significant scientific and technical data and information deemed to be of continuing reference value. NASA's counterpart of peerreviewed formal professional papers but has less stringent limitations on manuscript length and extent of graphic presentations.

- TECHNICAL MEMORANDUM. Scientific and technical findings that are preliminary or of specialized interest, e.g., quick release reports, working papers, and bibliographies that contain minimal annotation. Does not contain extensive analysis.

- CONTRACTOR REPORT. Scientific and technical findings by NASA-sponsored contractors and grantees.
- CONFERENCE PUBLICATION. Collected papers from scientific and technical conferences, symposia, seminars, or other meetings sponsored or cosponsored by NASA.

- SPECIAL PUBLICATION. Scientific, technical, or historical information from NASA programs, projects, and missions, often concerned with subjects having substantial public interest.

- TECHNICAL TRANSLATION. Englishlanguage translations of foreign scientific and technical material pertinent to NASA's mission.

Specialized services that complement the STI Program Office's diverse offerings include creating custom thesauri, building customized databases, organizing and publishing research results ... even providing videos.

For more information about the NASA STI Program Office, see the following:

- Access the NASA STI Program Home Page at http://www.sti.nasa.gov

- E-mail your question via the Internet to help@sti.nasa.gov

- Fax your question to the NASA Access Help Desk at 301-621-0134

- Telephone the NASA Access Help Desk at 301-621-0390

- Write to:

NASA Access Help Desk

NASA Center for AeroSpace Information 7121 Standard Drive

Hanover, MD 21076 
NASA/TM-2004-213063

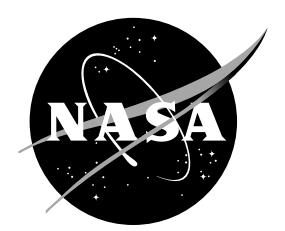

\section{Probabilistic Aeroelastic Analysis of Turbomachinery Components}

T.S.R. Reddy and S.K. Mital

University of Toledo, Toledo, Ohio

G.L. Stefko

Glenn Research Center, Cleveland, Ohio

National Aeronautics and

Space Administration

Glenn Research Center 


\section{Acknowledgments}

The authors would like to thank Dr. Shantaram Pai and Dr. Pappu L. Murthy, NASA Glenn Research Center, and

Dr. R. Srivastava, University of Toledo, for their suggestions. This work was supported with funding from

Smart Efficient Components project, Robert Corrigan, Program Manager, and from the Office of Safety and Assurance Technologies (Code Q), Jeffrey Rusick, Program Manager.

Available from

NASA Center for Aerospace Information 7121 Standard Drive

Hanover, MD 21076
National Technical Information Service 5285 Port Royal Road Springfield, VA 22100

Available electronically at http:/ /gltrs.grc.nasa.gov 


\title{
Probabilistic Aeroelastic Analysis of Turbomachinery Components
}

\author{
T.S.R. Reddy ${ }^{*}$ and Subodh K. Mital ${ }^{*}$ \\ The University of Toledo \\ Toledo, Ohio 43606 \\ George L. Stefko \\ National Aeronautics and Space Administration \\ Glenn Research Center \\ Cleveland, Ohio 44135
}

\begin{abstract}
A probabilistic approach is described for aeroelastic analysis of turbomachinery blade rows. Blade rows with subsonic flow and blade rows with supersonic flow with subsonic leading edge are considered. To demonstrate the probabilistic approach, the flutter frequency, damping and forced response of a blade row representing a compressor geometry is considered. The analysis accounts for uncertainties in structural and aerodynamic design variables. The results are presented in the form of probabilistic density function (PDF) and sensitivity factors. For subsonic flow cascade comparisons are also made with different probabilistic distributions, probabilistic methods, and Monte-Carlo simulation. The approach shows that the probabilistic approach provides a more realistic and systematic way to assess the effect of uncertainties in design variables on the aeroelastic instabilities and response.
\end{abstract}

\section{Introduction}

Two aeroelastic issues, high cycle fatigue (HCF) due to forced response and catastrophic failure due to flutter, are the drivers of component failures in modern military and civilian gas turbine engines. Accurate computation of these drivers requires an aeroelastic analysis that includes the interaction of unsteady aerodynamics and structural dynamics. A number of aeroelastic analysis codes have been developed for turbomachinery analysis by various federal agencies, industry and academia. However, these analysis codes at present are used in a design loop with uncertainties accounted for by using safety factors. This approach sometimes yields conservative designs, thereby reducing the potential of designing higher efficiency engines.

The currently available aeroelastic codes can accurately calculate a deterministic value of the flutter damping and a deterministic value of the forced response amplitude and provide a measure of dynamic stability and a measure of HCF life respectively. However, due to uncertainties in the manufacturing process, uncertainties exist in blade properties and thus a deterministic calculation can provide erroneous results. It is important to account for the uncertainties in order to better estimate the blade stability and life characteristics. The Air Force High Cycle Fatigue Group identified uncertainties that had lead to many HCF problems. These include uncertainty in anticipating the amplitude of the excitation, identifying the vibration mode and frequency, missing a low order mode, material defects and damage due to manufacturing, and boundary attachments of blades to disks, etc. A probabilistic analysis can, not only account for uncertainties in the properties of the structure but can also provide the probability of

\footnotetext{
*NASA Resident Research Associate at Glenn Research Center
} 
occurrence of a failure over the designed life providing the designer to make educated choices during design.

An integration of the deterministic aeroelastic analysis methods with probabilistic analysis methods offers the potential to reduce aeroelastic problems and will provide a quantum leap toward designing safe reliable engines. Probabilistic analysis will allow for more reliable and efficient engine designs. It also provides the values of the design allowables for a given reliability.

The objective of the proposed paper is to use the probabilistic methods to determine the factors that affect most the aeroelastic characteristics (forced response and stability) of a turbomachine component such as a fan, compressor, or turbine. The approach taken is to combine the aeroelastic analysis of MISER (MIStuned Engine Response) (ref. 1) with the fast probability integration (FPI) techniques available in NESSUS (Numerical Evaluation of Stochastic Structures Under Stress), ref. 2. The role of MISER is to provide the functional relationships that tie the structural and aerodynamic parameters (the primitive variables) to the forced response amplitudes and stability eigenvalues (the response properties). The role of FPI is to perform probabilistic analyses by utilizing the response properties generated by MISER. The results are cumulative distribution function (CDF's) for the response properties. A CDF is the relationship defined by the value of a response property with respect to its cumulative probability of occurrence. The probabilistic sensitivities of the response variables to uncertainty in primitive variables are obtained as a bye product of the FPI technique. It is to be noted that this is the first time that fast probabilistic methods are applied to perform a coupled structural and unsteady aerodynamic analysis.

The results are presented for two blade rows, one for subsonic flow, and one for supersonic flow with subsonic leading edge. A typical section structural model, with a mass spring is used for structural modeling.

\section{Formulation}

As previously mentioned, the present work adopts an integrated approach, which is a synergistic combination of two NASA Glenn supported research disciplines. The first methodology is concerned with MISER, an aeroelastic stability and response analysis code for turbomachines. The second one consists of an FPI technique that takes into account the uncertainties in structural and aerodynamic parameters of the turbomachine, and computes the cumulative probabilistic behavior of the aeroelastic system. A brief description of both the codes is given below.

\section{Aeroelastic Simulation}

In general, the components of a fan compressor or turbine have complex geometries. To accomplish the stated objectives of the paper, it is necessary to use a model that simplifies the analysis, yet maintains the basic structural and aerodynamic characteristics. The MISER code uses simple structural and aerodynamic models to calculate flutter eigenvalues and forced response magnitudes of two-dimensional model of turbomachine component, fan, compressor or turbine. Brief description of the models and governing equations of motion is given below.

\section{Structural model}

The structural model consists of a typical section with two degrees of freedom (bending and torsion) for each of the blades of a $\mathrm{N}$ blade cascade (figure 1). Each airfoil is suspended by bending and torsion springs, $k_{h}$ and $k_{\alpha}$, respectively. The airfoil is assumed to be rigid in the chordwise direction, and this 
motion is neglected. The elastic coupling between bending and torsion due to pretwist, shrouds, and rotation of the rotor could be modeled thorough the offset distance between the center of gravity and the elastic axis, $x_{a}$. The centrifugal stiffening effects due to rotation are included in the bending and torsion spring constants. The properties of the blades are represented by their values at 75 percent span. The elastic axis is at a distance $a_{h}$ from the mid-chord.

\section{Aerodynamic model}

The unsteady aerodynamic loads are calculated by using Smith's, ref. 3, theory in subsonic flow, and Adamczyk and Goldstein's, ref. 4, for supersonic flow with a subsonic leading edge. In these theories, the effect of airfoil thickness, camber, and steady state angle of attack are neglected, and the flow is assumed to be isentropic and irrotational. The effect of wakes shed from upstream periodic obstructions are included. The wakes are considered are limited to sinusoidal distortions represented by vorticity perturbations so that they are convected downstream at the flow velocity.

\section{Aeroelastic equations}

The equations of motion for the typical section with structural damping can be written in matrix form for the $s^{\text {th }}$ blade as:

$$
\left[M_{s}\right]\left\{\ddot{q}_{s}\right\}+\left[C_{s}\right]\left\{\dot{q}_{s}\right\}+\left[K_{s}\right]\left\{q_{s}\right\}=\left\{f_{a s}^{q}\right\}+\left\{f_{a s}\right\}
$$

where $\left\{f a^{q}\right\}$ denotes the aerodynamic loads due to blade vibration that may cause instability and $\{f a\}$ denotes motion-independent aerodynamic loads due to wakes (gust) leading to fatigue failures due to forced response.

For the two degrees of freedom considered here, eq. (1) for the $s^{\text {th }}$ blade can be rewritten as

$$
\left[\begin{array}{cc}
1 & x_{\alpha s} \\
x_{\alpha s} & r_{\alpha s}^{2}
\end{array}\right]\left\{\begin{array}{c}
\ddot{h}_{s} / b \\
\ddot{\alpha}_{s}
\end{array}\right\}\left[\begin{array}{cc}
2 \omega_{h s} \zeta_{h s} & 0 \\
0 & 2 r_{\alpha s}^{2} \omega_{\alpha s}^{2} \zeta_{\alpha s}
\end{array}\right]\left\{\begin{array}{c}
\dot{h}_{s} / b \\
\dot{\alpha}_{s}
\end{array}\right\}+\left[\begin{array}{cc}
\omega_{h s}^{2} & 0 \\
0 & r_{\alpha s}^{2} \omega_{\alpha s}^{2}
\end{array}\right]\left\{\begin{array}{c}
h_{s} / b \\
\alpha_{s}
\end{array}\right\}=\left\{\begin{array}{c}
f_{h s} / m_{s} b \\
f_{\alpha s} / m_{s} b^{2}
\end{array}\right\}
$$

where $m$ is the mass of the blade per unit length, $h$ is the plunging (bending) displacement normal to the chord, $\alpha$ is the pitching (torsion) displacement, $x_{\alpha}$ is the distance between the elastic axis and center of

mass in semi-chord units; $r_{\alpha}$ is the radius of gyration about the elastic axis in semi-chord units; $\zeta_{h}$ and $\zeta_{\alpha}$ are the damping ratios; $b$ is the airfoil semi-chord; $f_{h}$ and $f_{\alpha}$ are the aerodynamic loads; $\omega_{h}$ is the uncoupled natural frequency for bending; $\omega_{\alpha}$ is the uncoupled natural frequency for torsion which are related to $k_{h}$ and $k_{\alpha}$ as

$$
\omega_{h}=\sqrt{k_{h} / m} \text { and } \omega_{\alpha}=\sqrt{k_{\alpha} / I_{\alpha}}
$$

For a tuned cascade (or rotor), in which all the blades are identical, the aeroelastic modes consist of individual blades vibrating with equal amplitudes with a fixed interblade phase angle between adjacent blades. The values of the interblade phase angles, $\sigma_{r}$, are given by, ref. 5 ,

$$
\sigma_{r}=2 \pi r / N ; r=0,1,2, \ldots \ldots, N-1
$$


where $N$ is the number of blades in the cascade.

Hence, for this problem, the motion of the typical blade is written as

$$
\left\{\begin{array}{c}
h_{s} / b \\
\alpha_{s}
\end{array}\right\}=\left\{\begin{array}{c}
h_{0 s} / b \\
\alpha_{0 s}
\end{array}\right\} e^{i \omega t}=\left\{\begin{array}{c}
h_{a r} / b \\
\alpha_{a r}
\end{array}\right\} e^{i \omega t} e^{i \sigma_{r} s}
$$

Thus the equation for the blade becomes

$$
-\left[M_{s}\right]\left\{\begin{array}{c}
h_{a r} / b \\
\alpha_{a r}
\end{array}\right\} e^{i\left(\omega t+\sigma_{r} s\right)}+\lambda\left[K_{s}\right]\left\{\begin{array}{c}
h_{a r} / b \\
\alpha_{a r}
\end{array}\right\} e^{i\left(\omega t+\sigma_{r} s\right)}=\left[A_{r}\right]\left\{\begin{array}{c}
h_{a r} / b \\
\alpha_{a r}
\end{array}\right\} e^{i\left(\omega t+\sigma_{r} s\right)}+\left\{A D_{r}\right\} e^{i\left(\omega t+\sigma_{r} s\right)}
$$

where

$$
\begin{gathered}
{\left[M_{s}\right]=\mu_{s}\left[\begin{array}{cc}
1 & x_{\alpha} \\
x_{\alpha} & r_{\alpha}^{2}
\end{array}\right]} \\
{\left[K_{s}\right]=\left[\begin{array}{cc}
\left(\omega_{h s} / \omega_{o}\right)^{2}\left(1+2 i \zeta_{h s}\right) & 0 \\
0 & r_{\alpha s}^{2}\left(\omega_{h s} / \omega_{o}\right)^{2}\left(1+2 i \zeta_{\alpha s}\right)
\end{array}\right]} \\
{\left[A_{r}\right]=\left[\begin{array}{l}
l_{h h r} l_{h \alpha r} \\
l_{h \alpha r} l_{\alpha \alpha r}
\end{array}\right] ;\left\{A D_{r}\right\}=\left\{\begin{array}{l}
l_{w h r} \\
l_{w \alpha r}
\end{array}\right\}}
\end{gathered}
$$

$\lambda=\left(\omega_{o} / \omega\right)^{2}$

$\mu=m / \pi \rho b^{2}$

$\omega_{o}=$ reference frequency, $\rho$ is the air density, and the damping terms are approximated as,

$$
\begin{aligned}
& 2 i \omega \omega_{h s} \zeta_{h s} \approx 2 i \omega_{h s}^{2} \zeta_{h s} \\
& 2 i r_{\alpha s}^{2} \omega \omega_{\alpha s} \zeta_{\alpha s} \approx 2 i r_{\alpha s}^{2} \omega_{\alpha s}^{2} \zeta_{\alpha s}
\end{aligned}
$$

The elements of $[M]$ and $[K]$ are obtained from the structural properties, and the elements of $[A]$ and $[A D]$ are obtained from ref. 3 for subsonic flow, and from ref. 4 for supersonic flow with subsonic leading edge locus.

Since the blades are identical, the same equation is obtained for each blade. Thus, no additional information can be obtained by assembling the equations for all the blades on the disk. Instead, eq. (5) is solved for $N$ different values of the interblade phase angle given by eq. (3) for stability and response.

\section{Probabilistic Simulation}

There are a number of approaches available for obtaining a probabilistic response from a set of independent variables and the expressions describing the response behavior. Monte-Carlo simulation is one such fairly common technique for obtaining the cumulative distribution functions (CDF's) given the probability distributions of independent variables. In this technique, randomly selected values of the input variables, which are based on their known probabilistic distributions, are used to deterministically compute the value of the response variable. This has to be repeated usually several hundreds or even 
thousands of times to build the response probabilistic characteristics. In essence, this technique requires a large number of simulations to generate CDF's of output variables. Although, inherently simple, the large number of output sets that must be generated to obtain a reasonably accurate CDF of output variables becomes its obvious disadvantage. NASA Glenn Research Center has been involved in developing efficient probabilistic methods for more than a decade. As a result of this research initiative, fast probability integration (FPI) algorithms were developed (ref. 2) to solve a large class of engineering problems.

Let $Z$ be the response function of ' $n$ ' random variables given by

$$
Z(X)=Z\left(X_{1}, X_{2}, \ldots \ldots, X_{n}\right)
$$

where $Z$ represents the response variable and $X$ represents the random variable. The goal of the probabilistic analysis is to compute the probability that $Z$ will have a value less than or equal to a given magnitude $Z_{0}$. To achieve this goal, the performance function, which describes how the mechanics of the system behaves, can be cast as a limit state function $g(X)$, which can be described as

$$
g(X)=Z(X)-Z_{0}
$$

Traditionally, the limit state function ' $\mathrm{g}$ ' has been defined in such a way that $g=0$ represents a boundary where $g<0$ represents failed region and $g>0$ represents safe region. Here the objective would be to compute $P[g(X) \leq 0]$. Generally speaking, $Z_{0}$ describes a limit indicating failure, $g(X)$ is called a failure function, or in a classical sense, the probability of the stress exceeding the strength.

Given the probability density function $f x(x)$ of the limit state function $g(x)$, we can formulate the limit state probability $P[g \leq 0]$ as

$$
P_{f}=P[g(X) \leq 0]=\int_{\Omega} \ldots . . \int_{x}(x) d x
$$

where $\Omega$ describes the domain of integration. This multiple integration is, in general, very difficult to integrate analytically. However, FPI has been found to be an excellent tool to evaluate eq. (9) efficiently and accurately.

\section{Implementation of Probabilistic Procedure Using FPI}

A brief schematic of the FPI input/output scheme is shown in fig. 2. It is a probabilistic analysis tool that implements a variety of methods for probabilistic analysis. The procedure for the probabilistic analysis is as follows:

(1) Identify the independent and uncorrelated design (primitive) variables with uncertainties (i.e. identify the risk elements)

(2) Quantify the uncertainties of these design variables with probability distributions based on expert opinion elicitation, historical data or benchmark/prototype testing etc.

(3) It is required that there is a response function (sometimes called a performance function) that defines the relationship between the response and the independent variables. For the present study, the solution from the MISER code defines the response function that relates the structural and aerodynamic design variables to the response. For an aeroelastic analysis the flutter eigenvalues that indicate aerodynamic damping and forced response amplitude are the response quantities. 
(4) For a given set of values of primitive variables, the MISER code is used to generate the desired response variables. The whole process is repeated a number of times to generate a table of response variable values that correspond to the perturbed values of the primitive variables. Number of simulations needed depends upon the method used and the number of random variables, but they are far less than what would be required in a standard Monte-Carlo technique.

(5) The FPI then uses the table of responses generated above to compute the CDF/probability density function (PDF) and the corresponding sensitivities of the response.

Several methods are available in the FPI to compute a probabilistic distribution. In addition to obtaining the CDF/PDF of the response, the FPI provides additional information regarding the sensitivity of the response with respect to the primitive variables. They provide valuable information in controlling the scatter of the response variable. The random primitive variable with the highest sensitivity factor will yield the biggest payoff in controlling the scatter in that particular response variable. Such information is very useful to the test/design engineer to direct the resources in terms of measurements.

\section{Results and Discussion}

A 12 bladed cascade is considered for the aeroelastic analysis and for the subsequent probabilistic analysis. The design parameters that are involved in the problem are given in Table 1 and Table 2 giving a total of 11 design variables. Uncertainties may exist in any of the design variables. In the present analysis, six variables given in Table1 are considered for the probabilistic analysis. For subsonic flow cascade, the aeroelastic analysis results for both flutter and response are presented. For supersonic flow cascade only flutter calculations are presented.

It should be noted that for the example chosen, the elastic axis (see fig. 1) is at midchord, i.e. $a_{h}=0.0$. The distance between the elastic axis and center gravity, $x_{\alpha}$, is also zero, indicating that coupling between bending and torsion is very weak and the flutter mode is dominated by torsional motion. Therefore, only torsion mode is shown for all the calculations. The Mach numbers considered are 0.7 for subsonic flow and 1.2 for supersonic flow with subsonic leading edge. Flat plate airfoils are considered for the present purpose. The unsteady aerodynamic coefficients for the aeroelastic analysis are obtained using Smith code, ref. 3, for subsonic flow, and from Adamczyk and Goldstein code, ref. 4, for supersonic flow with subsonic leading edge.

\section{Design and Response Variables for the Numeric Example}

The design variables with their notation in brackets are:

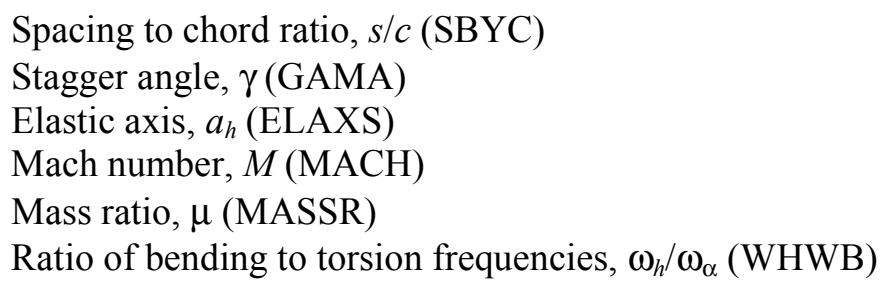

In these parameters, the elastic axis, and the ratio of bending to torsion frequencies depend on the structural characteristics, while spacing to chord ratio, stagger angle, and Mach number affect the aerodynamic forces. The mass ratio, the ratio of the structural mass to aerodynamic mass depends on both material density and air density. Air density in turn depends on the pressure ratio and temperature. The assumed mean values and standard deviations of these variables are given in table 1 . These variables are 
assumed to be independent and assumed to have normal distributions. However, once the sensitivity factors are given, the variables that turn out to be important should be investigated further. The other parameters in the analysis are assumed to be deterministic and the values are given in table 2. The response variables are:

\author{
flutter frequency \\ flutter damping \\ forced response amplitude
}

In the following, results will be presented for cascades in subsonic and supersonic flow both from deterministic and probabilistic analysis. The deterministic analysis gives one value of damping and frequency for the given values of the design variables. This value of damping and frequency will determine the amount of structural damping to be added to make the cascade stable or reduce the response amplitude. However, the design variables in reality exhibit some variation in their values since it is impractical to manufacture the blades for a given value. The deterministically calculated damping and frequency may not be the real value that exists in operation because of the uncertainty in the design values. The predicted positive damping for the stable cascade may not be the actual value available in real application. The predicted negative damping may not be the real value, and may affect the real amount of structural damping to be added for the rotor to be stable. It should be noted that damping and frequency affect both stability, and response amplitudes of the blades.

\title{
Subsonic Flow Cascade
}

Deterministic flutter calculation.-Figure 3 shows that root locus plot for the 12 phase angles for the reduced frequency, $k_{b}$, of 0.1 and 0.3 respectively for the torsional mode. The reduced frequency, $k_{b}$, is defined as $k_{b}=\omega b / V$, where $\omega$ is the frequency, $b$ is the semichord and $V$ is the flow velocity. The phase angles are $0,30,60,90,120,150,180,210,240,270,300$, and 330 degrees. It can be seen that the cascade is stable for $k_{b}=0.3$ and unstable for $k_{b}=0.1$ for about five phase angles, with the critical phase angle equal to 60 degrees. It is necessary that structural damping has to be added to make the cascade stable for $k_{b}=0.1$.

In the following probabilistic analysis will be done for both unstable and stable cascade for 60 degree phase angle to predict how much the variation in damping and frequency with variation included in the design variables. Probabilistic analysis gives the variation of the predicted damping and frequency with variation, and information on what design variable affect these values. Then the manufacturer can control the variation in these design variables so that the predicted damping is as close to the one predicted by deterministic calculation. It was noted that the critical phase angle did not change for the standard deviations considered for the variables considered.

\section{Probabilistic flutter calculation.}

Unstable cascade, $k_{b}=0.1$ : The probability density function (pdf) of damping is shown in figure 4.1. All the six design variables are assumed to be of normal distribution. First Order reliability Method (FORM) is used for the probabilistic analysis. The predicted mean value of damping is 0.0787 with a standard deviation (std. dev.) of 0.0078 and a scatter range of four standard deviations from the mean. Probabilistic sensitivity factors of damping at 0.978 probability level are shown in figure 4.2 . It shows that GAMA and SBYC are most sensitive variables. Therefore, to keep tighter tolerances on damping, greater quality control of the variables GAMA and SBYC must be exercised. Figure 5.1 shows the pdf of frequency. The scatter range of the frequency is about 3.5 standard deviations from the mean with the mean values and standard deviation as shown in the figure. Sensitivity factors at probability level of 0.999 in fig. 5.2 show very dramatically that ELAXS pretty much controls the scatter in the frequency for this case. One would need to control the uncertainties in ELAXS to control the scatter in the frequency. The deterministic analysis has shown that an addition of structural damping (ratio) of 0.0787 would have been 
sufficient for the cascade to be stable. The probabilistic analysis has shown the variation of this damping value with uncertainties, and the chance of the cascade to be unstable even after adding 0.0787 structural damping (ratio).

Effect of the distribution type on PDF of flutter: For the results shown above a normal distribution was assumed for the six selected design variables. However, the actual distribution types are unknown. It is decided to perform a limited set of study to investigate what would be the effect of different distribution types on flutter damping and frequency. The distribution types are varied for the random variables SBYC, GAMA and MACH. Figure 6.1 shows the pdf of flutter damping plotted for various distributions denoted respectively for SBYC, GAMA and MACH. The distributions are $\mathrm{W}$ for Weibull, $\mathrm{N}$ for Normal, EV1 for Extreme Value Distribution (Type 1), and LN for log normal. It can be seen that there is negligible difference from different distributions. The variation of flutter frequency is shown in fig. 6.2. The distributions are varied for ELAXS, MACH and MASSR and denoted respectively in fig. 6.2. A slight effect of the distribution type is seen on the pdf of frequency than on the pdf of damping.

Comparison of analysis methods: The effect of probabilistic analysis methods is compared next. Figure 7 shows the comparison of flutter damping obtained by using three probabilistic methods of analysis, namely First Order reliability Method (FORM), Advanced Fast Probability Integration-3 parameter normal, AFPI, and Monte-Carlo (MC) simulation. Normal distribution is assumed for all the six design variables. The MC simulation was run for 100,000 samples using FPI program. It shows that the pdf predicted by FORM and AFPI methods correlates well with that predicted by Monte Carlo method.

In the results to follow, all the variables are assumed to have normal distribution, and the FORM method is used for probabilistic analysis.

Stable cascade, $k_{b}=0.3$ : Figures 8.1-8.2 and 9.1-9.2 show the probability density functions and the sensitivity factors for the damping and the frequency for this case. Sensitivity factors for the damping are very different than for the case where $k_{b}=0.1$. For this case, ELAXS is the most sensitive random variable. The frequency analysis shows that ELAXS continues to be the most dominating variable for the frequency (fig. 9.2). It shows that controlling the scatter in SBYC, GAMA and to some extent MACH will have little effect in controlling the scatter in frequency.

Deterministic forced response calculation.-Figure 10 shows the tuned aeroelastic forced response obtained using linear (Smith) theory for vortical gust disturbance. Again a twelve-blade $(N=12)$ cascade with the same structural properties used for flutter calculations is considered. The response is shown for $\sigma=180$ degrees for flat plate geometry. This is equivalent to a 6 th engine order forcing function for the rotor. The unsteady aerodynamic coefficients are obtained at $k_{b}=0.3$ for which the cascade is aeroelastically stable in both the modes. The forcing frequency range investigated is limited to a small range around the uncoupled torsional frequency. For the tuned cascade all the blades will have equal amplitudes. The amplitude of response is a function of $\omega / \omega_{0}$ and is maximum at $\omega / \omega_{0}=0.93$ for which the probabilistic analysis is presented below.

Probabilistic forced response calculation.-Figure 11.1 shows the cumulative distribution function of torsional response amplitude with the mean value and standard deviation (std. dev.) as shown in the figure. The scatter range of this amplitude is between 0 and 2.0. It shows a significant scatter and as per the sensitivity analysis at probability level (prob. level) of 0.005 (fig. 11.2), ELAXS is again the most dominating random variable. Any effort to control the scatter in amplitude at 0.005 probability level should focus on controlling the uncertainty in ELAXS.

\section{Supersonic Flow With Subsonic Leading Edge Locus Cascade}

A cascade in supersonic flow with subsonic leading edge is characterized by the presence of shock waves in front of the cascade. Most of the current fans, rotors are designed for this flow regime.

Deterministic flutter calculation.-Again a 12 bladed cascade is considered. The free stream velocity is 1.2 , with a stagger angle of 45 degrees results in supersonic flow with subsonic leading edge. Figure 12 
shows that root locus plot for the 11 phase angles for the reduced frequency, $k_{b}$, of 0.3 for the torsion mode. The cascade is unstable for this value of $k_{b}$, unlike for subsonic flow cascade for which the cascade is stable. Also the analysis showed numerical instability for 240 degree phase angle, which is not included in fig. 12. The phase angles are $0,30,60,90,120,150,180,210,270,300$, and 330 degrees. It can be seen that the cascade is unstable for about three phase angles, with the critical phase angle equal to 30 degrees. It is necessary that structural damping has to be added to make the cascade stable. In the following probabilistic analysis is performed for the cascade.

Probabilistic flutter calculation.-The probability density function (pdf) of damping is shown in figure 13.1. The mean value of damping is 0.0108 with a standard deviation (std. dev.) of 0.0028 and the scatter of the damping is varies from 5.1 to 4.9 standard deviations. Probabilistic sensitivity factors of damping at 0.978 probability level are shown in figure 13.2. It shows that GAMA, ELASX and MACH are most sensitive variables. To control the scatter in damping, the biggest payoffs would result by controlling the scatter in these two random variables. Figure 14.1 shows the pdf of frequency. The scatter range of the frequency is from 0.95 to 1.012 with the mean values and standard deviation as shown in the figure. Sensitivity factors at probability level of 0.978 in fig. 14.2 show very dramatically that ELAXS pretty much controls the scatter in the frequency for this case. One would need to control the uncertainties in ELAXS to control the scatter in the frequency.

\section{Concluding Remarks}

In the present study, the probabilistic analysis methods available in FPI are used to investigate the probabilistic characteristics of subsonic and supersonic cascades. A typical section structural model with plunging and pitching degrees of freedom, and a linear unsteady cascade aerodynamic model were used in the aeroelastic calculations. Out of 12 identified design variables, six variables are assumed to have probabilistic variation. Their effect on flutter damping, flutter frequency, and response was presented. It was noted that the damping, frequency and response calculated with deterministic approach varied as much as 35 percent with assumed probabilistic variation.

\section{References}

(1) Kielb, R.E. and Kaza, K.R.V., "Aeroelastic Characteristics of a Cascade of Mistuned Blades in Subsonic and Supersonic Flows," ASME Journal of Vibration, Acoustics, Stress and Reliability of Design, vol. 105, pp. 425-433, Oct. 1983.

(2) Wu, Y.-T., "Computational Methods for Efficient Structural Reliability and Reliability Sensitivity Analysis," AIAA Journal., vol. 32, no. 8, Aug. 1994, pp. 1717-1723.

(3) Smith, S.N., "Discrete Frequency Sound Generation in Axial Flow Turbomachines," British Aeronautical Research Council, London, ARC R\&M No. 3709, 1971.

(4) Adamczyk, J.J. and Goldstein, M.E., "Unsteady Flow in a Supersonic Cascade with Subsonic Leading-Edge Locus,” AIAA Journal, vol. 16, no. 12, Dec. 1978, pp. 1248-1254.

(5) Lane, F., "Supersonic Flow past an Oscillating Cascade with Supersonic Leading-Edge Locus," Journal of the Aeronautical Sciences, vol. 24, pp .65-66, Jan. 1957. 
Table 1.-Design variables with uncertainties

\begin{tabular}{|l|c|c|c|c|}
\hline \multicolumn{1}{|c|}{ Design variable } & $\begin{array}{c}\text { Deterministic } \\
\text { value }\end{array}$ & Mean & $\begin{array}{c}\text { Standard } \\
\text { deviation }\end{array}$ & Distribution \\
\hline Spacing to chord ratio $(s / c)$ & 1.0 & 1.0 & $5 \%$ & Normal \\
Stagger angle $(\gamma)$ & 45.0 & 45.0 & $5 \%$ & Normal \\
Elastic axis $\left(a_{h}\right)$ & 0.0 & 0.0 & $10 \%$ & Normal \\
Mach number $(M)$ & 0.7 & 0.7 & $5 \%$ & Normal \\
Mass ratio $(\mu)$ & 1.2 & 1.2 & & \\
Ratio of bending to torsion frequency $\left(\omega_{h} / \omega_{\alpha}\right)$ & 258.5 & 258.5 & $5 \%$ & Normal \\
& 0.357 & 0.357 & $5 \%$ & Normal \\
\hline
\end{tabular}

Table 2.- Other design variables.

\begin{tabular}{|l|c|}
\hline \multicolumn{1}{|c|}{ Variable } & Value \\
\hline Structural damping & 0.0 \\
Bending mode $\left(\zeta_{h}\right)$ & 0.0 \\
Torsion mode $\left(\zeta_{\alpha}\right)$ & 0.5774 \\
\hline Radius of gyration about cg. $\left(r_{\alpha}\right)$ & 0.0 \\
\hline Distance between elastic axis and c.g. $\left(x_{\alpha}\right)$ & $0.1,0.3$ \\
\hline Reduced frequency based on semichord $\left(k_{b}\right)$ & \\
\hline
\end{tabular}

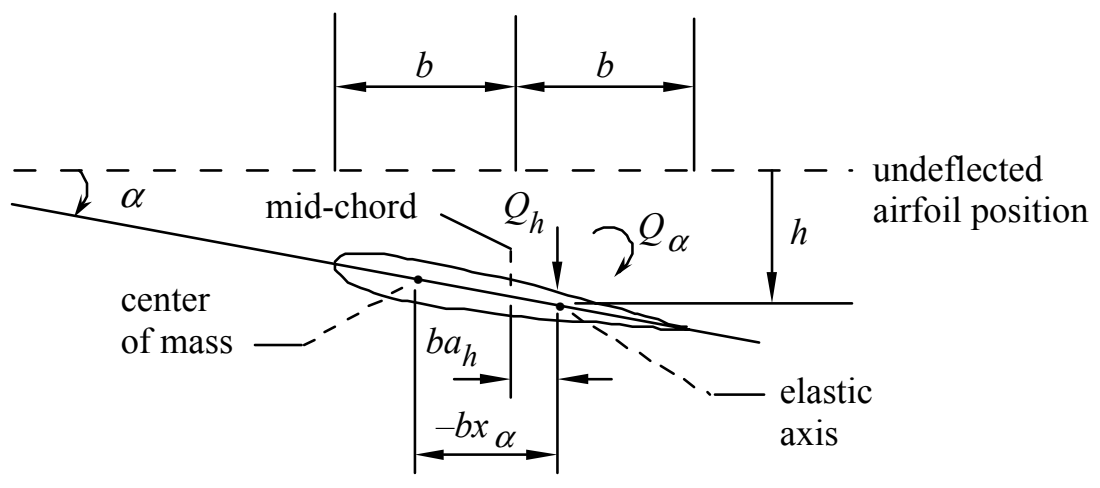

Figure 1.-Typical section blade model with two degrees-of-freedom. 


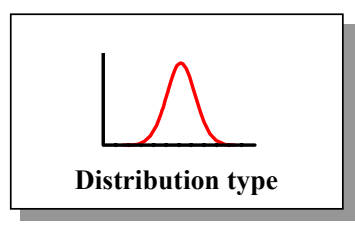

Random variable statistics
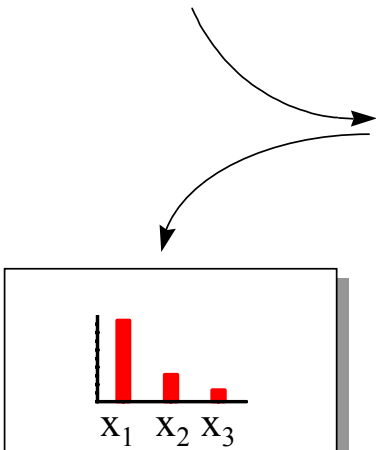

Sensitivity factors

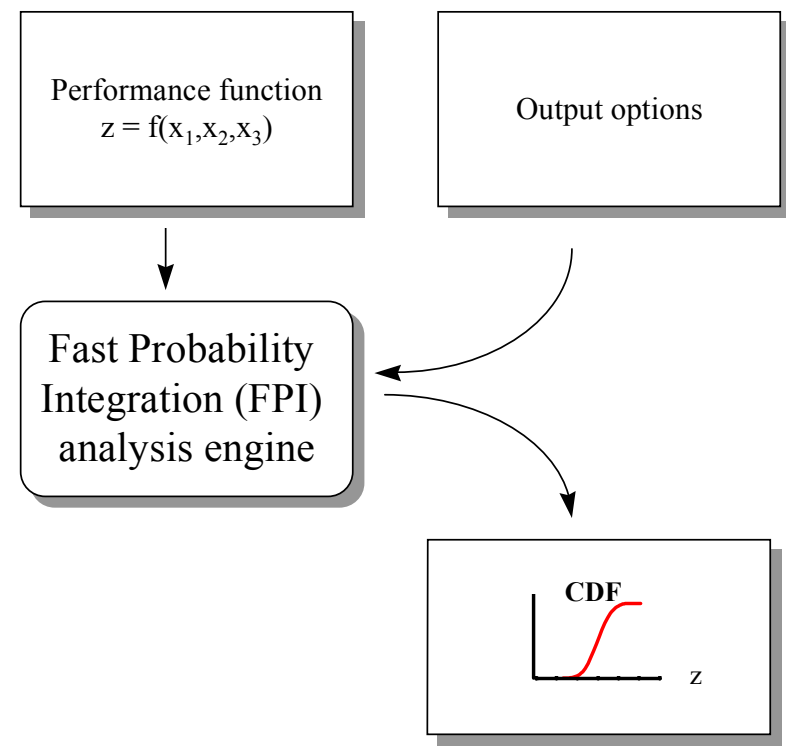

Response cumulative distribution function (CDF)

Figure 2.-Fast probability Integration input/output schematic.

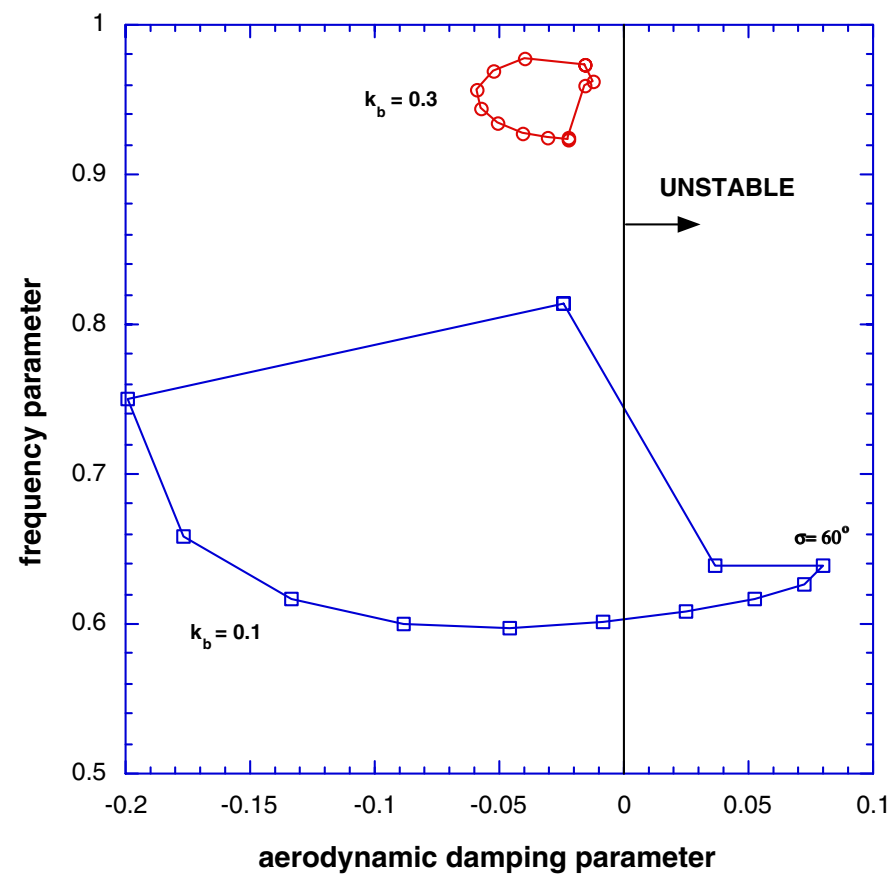

Figure 3.- Root locus plot for a 12 bladed cascade, Subsonic flow, $N=12, M=0.7$, torsion mode, structural damping ratio $=0.0$ 


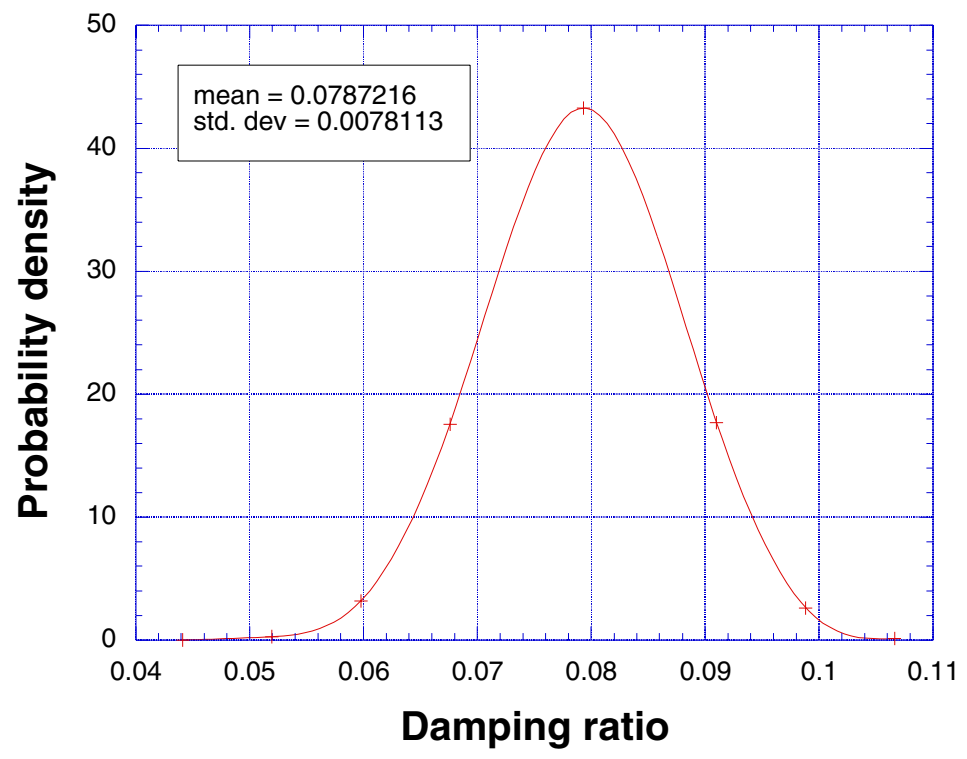

Figure 4.1.-Probability density function of damping $\left(k_{b}=0.1\right.$, torsion mode).

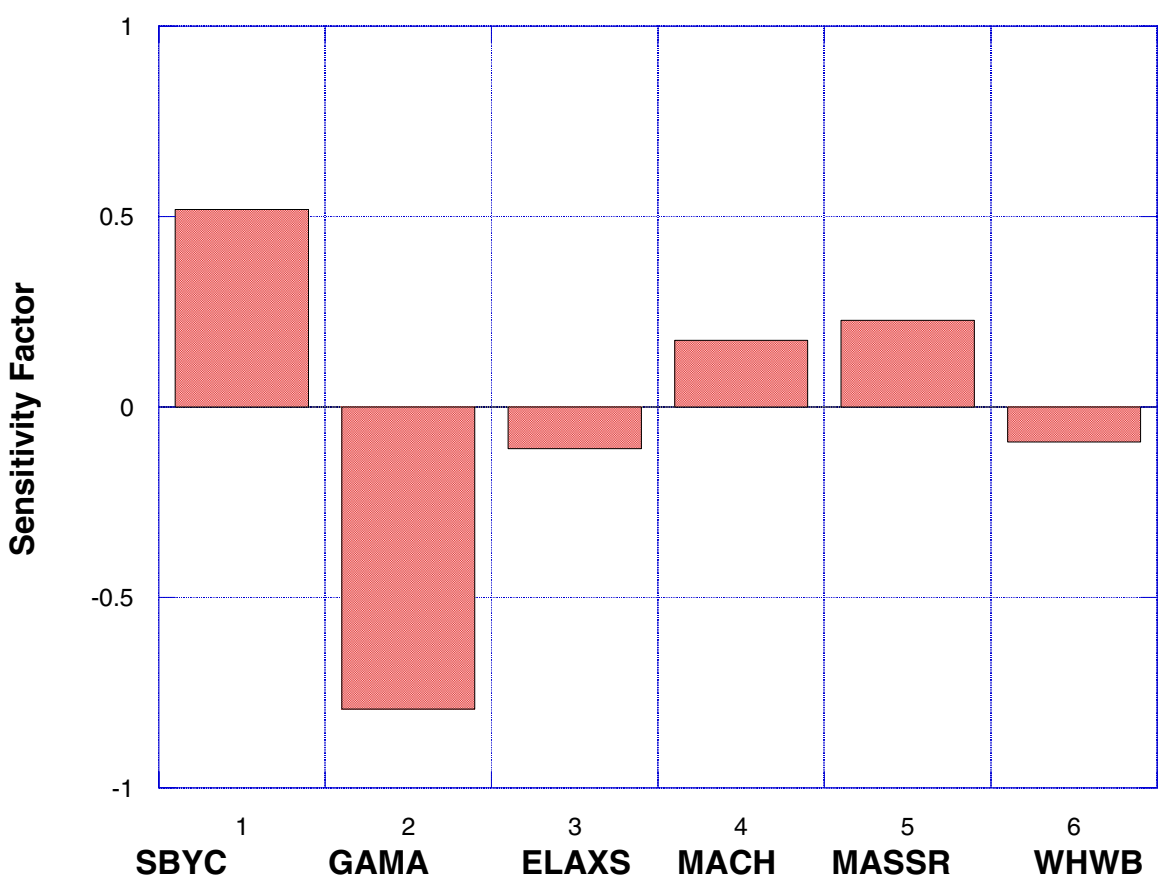

Figure 4.2.- Sensitivity factors of damping (prob. level 0.9734). 


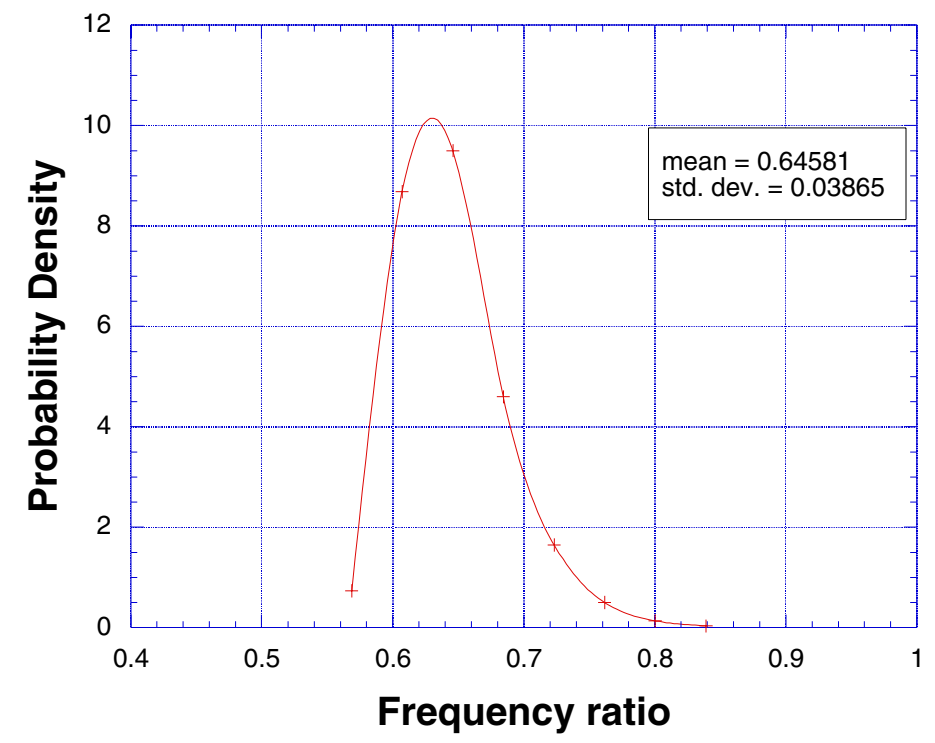

Figure 5.1.-Probability density function of frequency $\left(k_{b}=0.1\right.$, torsion mode).

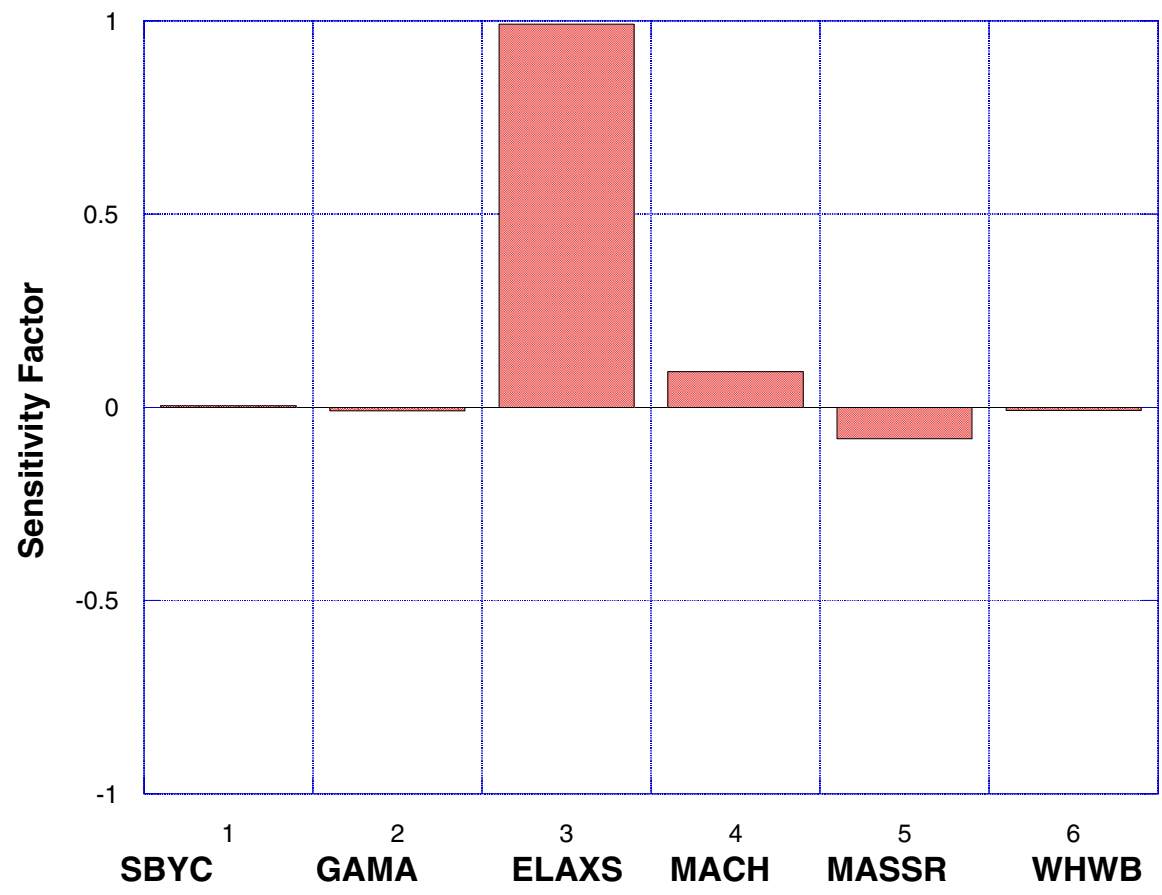

Figure 5.2.-Sensitivity factors of frequency (prob. level 0.999). 


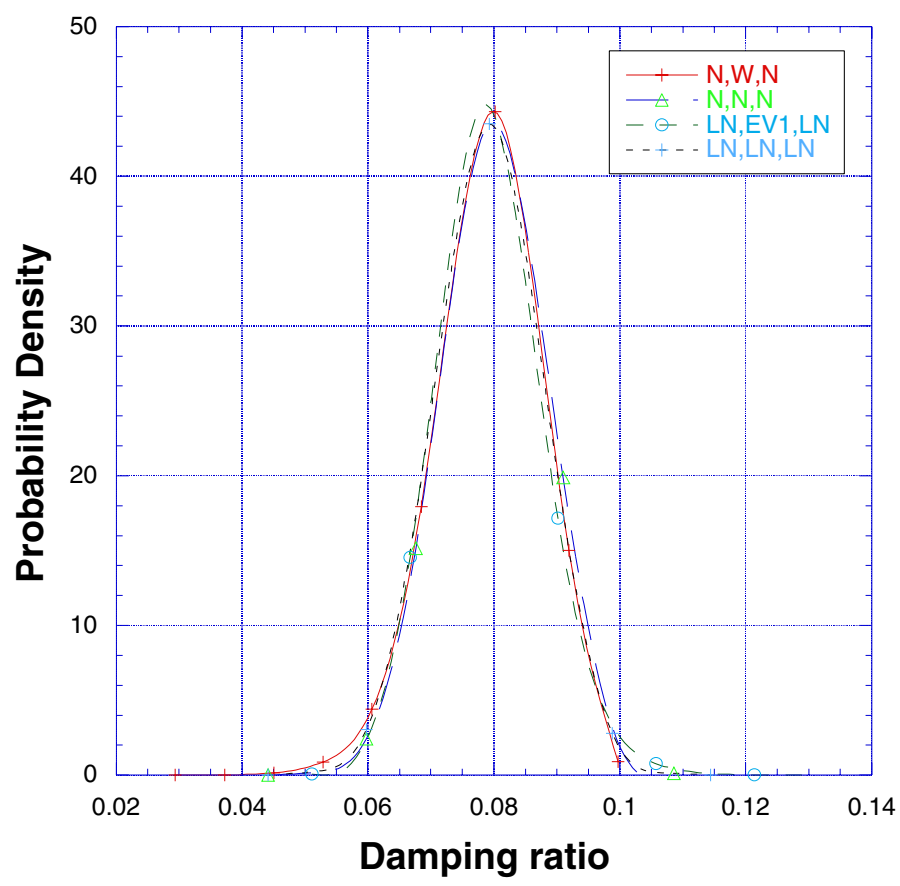

Figure 6.1.- Variation of pdf of damping with different distributions for the design variables

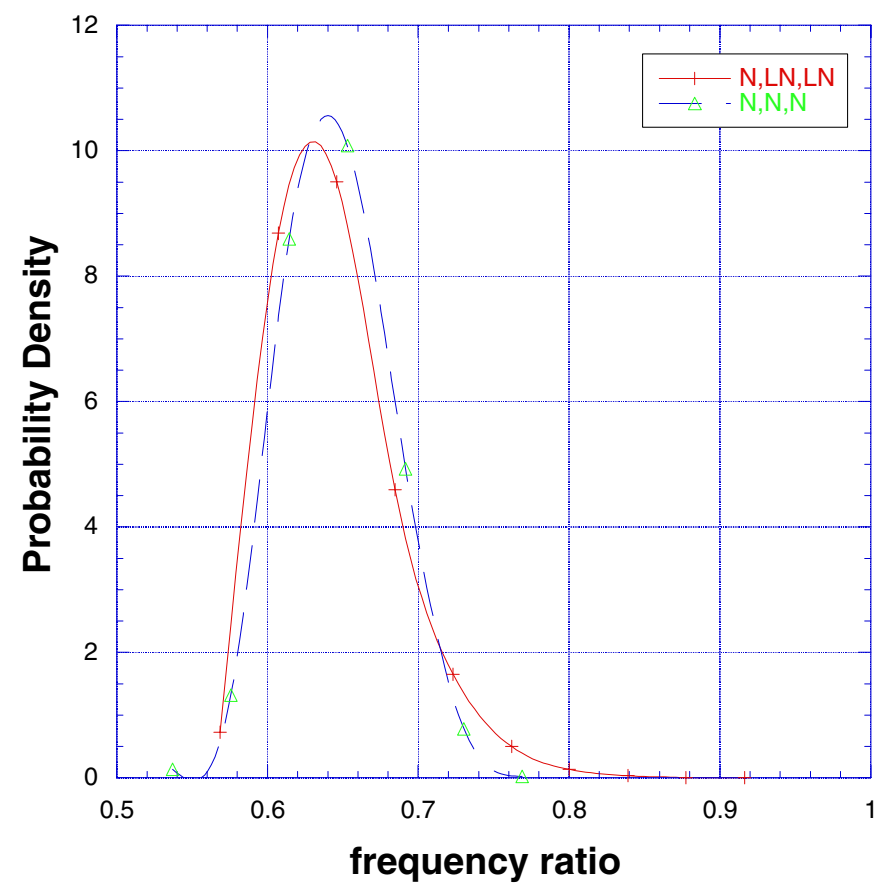

Figure 6.2.- Variation of pdf of frequency with different distributions for the design variables. 


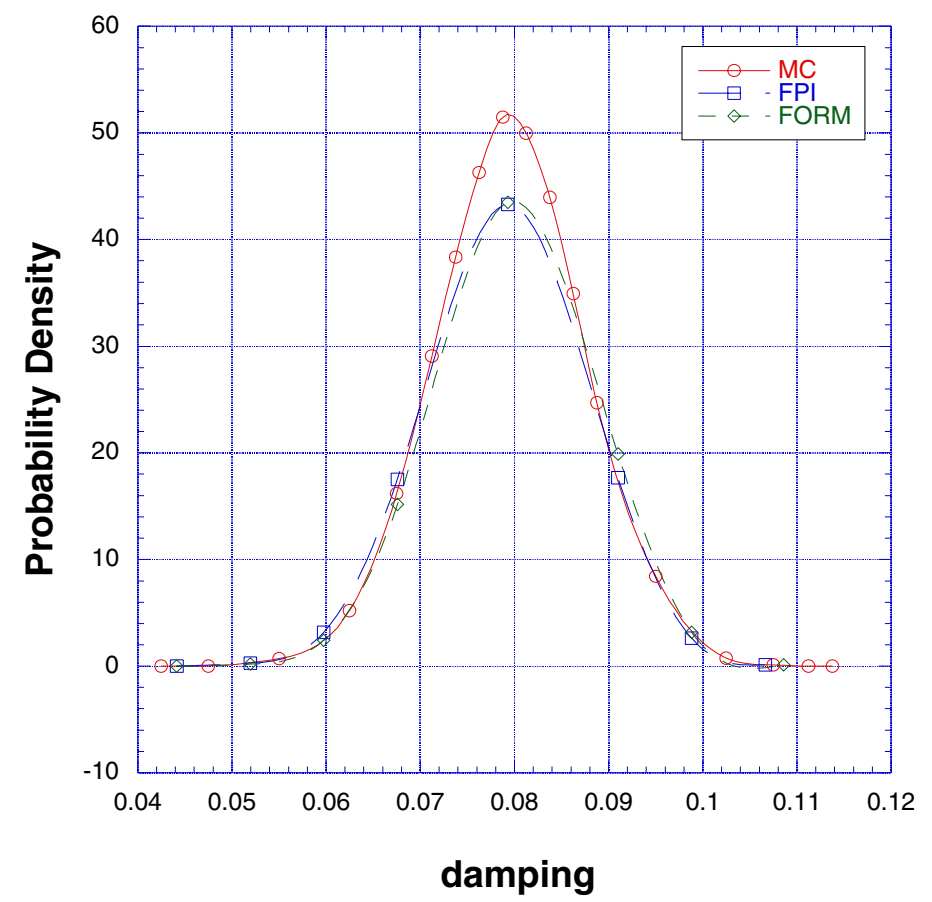

Figure 7.-Comparison of damping ratio from three probabilistic analysis methods.

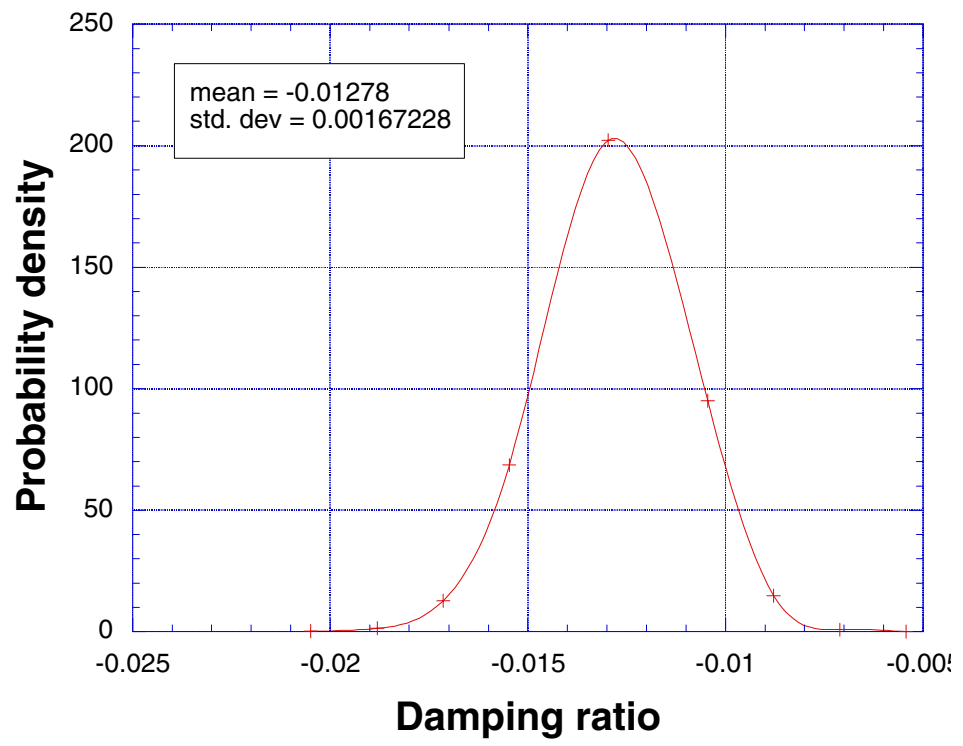

Figure 8.1.-Probability density function of damping ( $k_{b}=0.3$, torsion mode). 


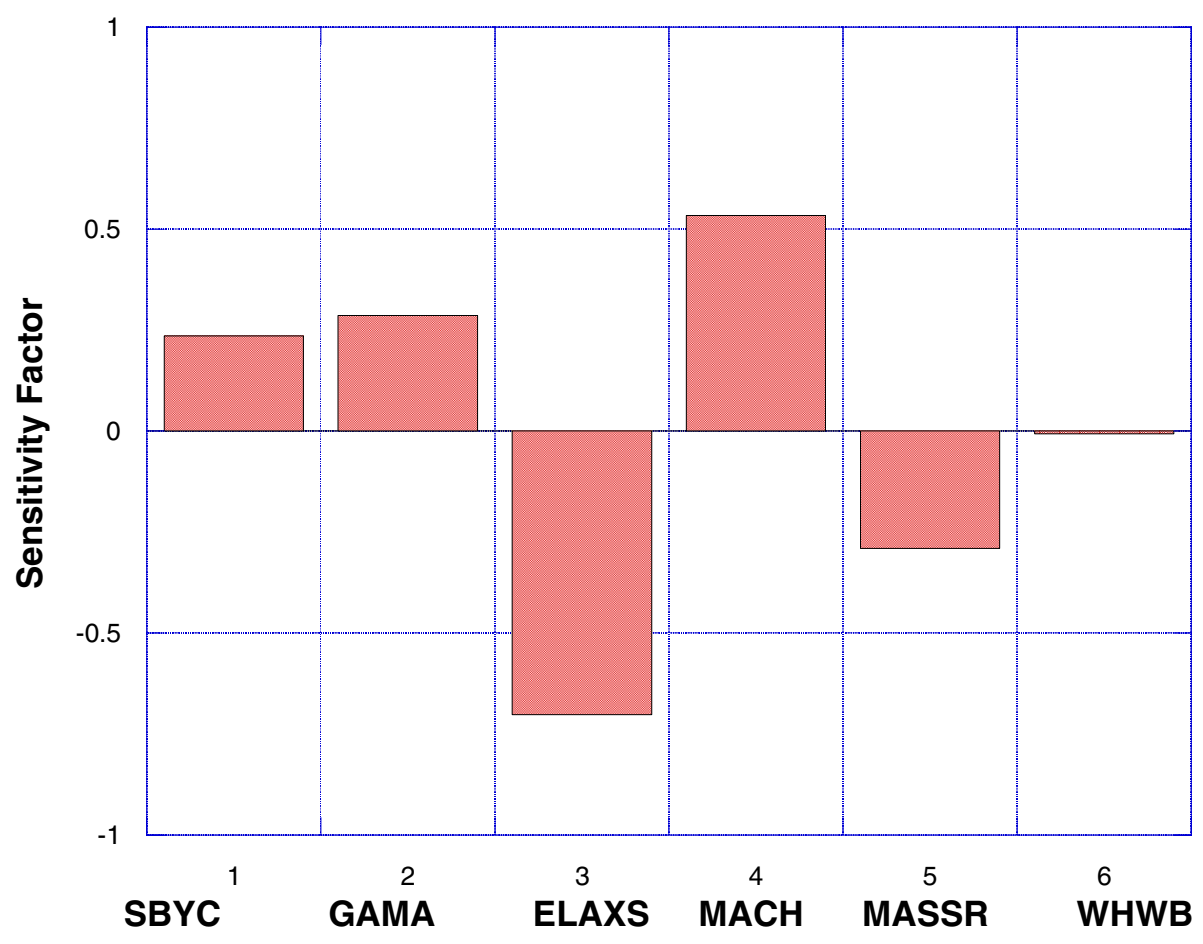

Figure 8.2 Sensitivity factors of damping (prob. level 0.998)

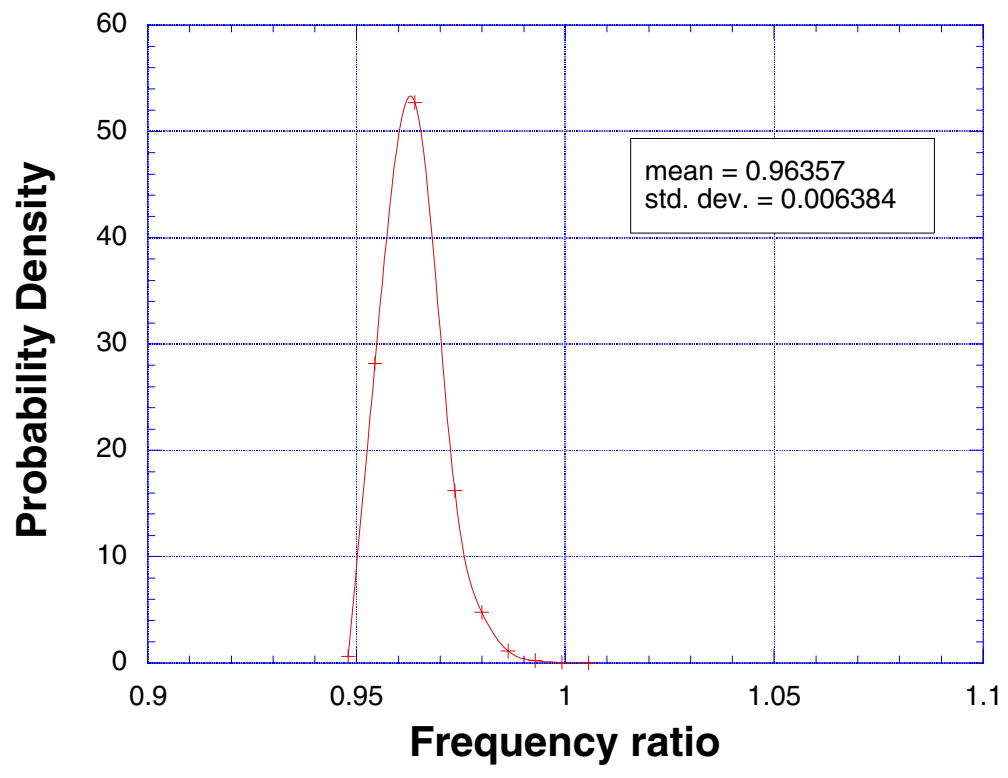

Figure 9.1.-Probability density function of frequency $\left(k_{b}=0.3\right.$, torsion mode). 


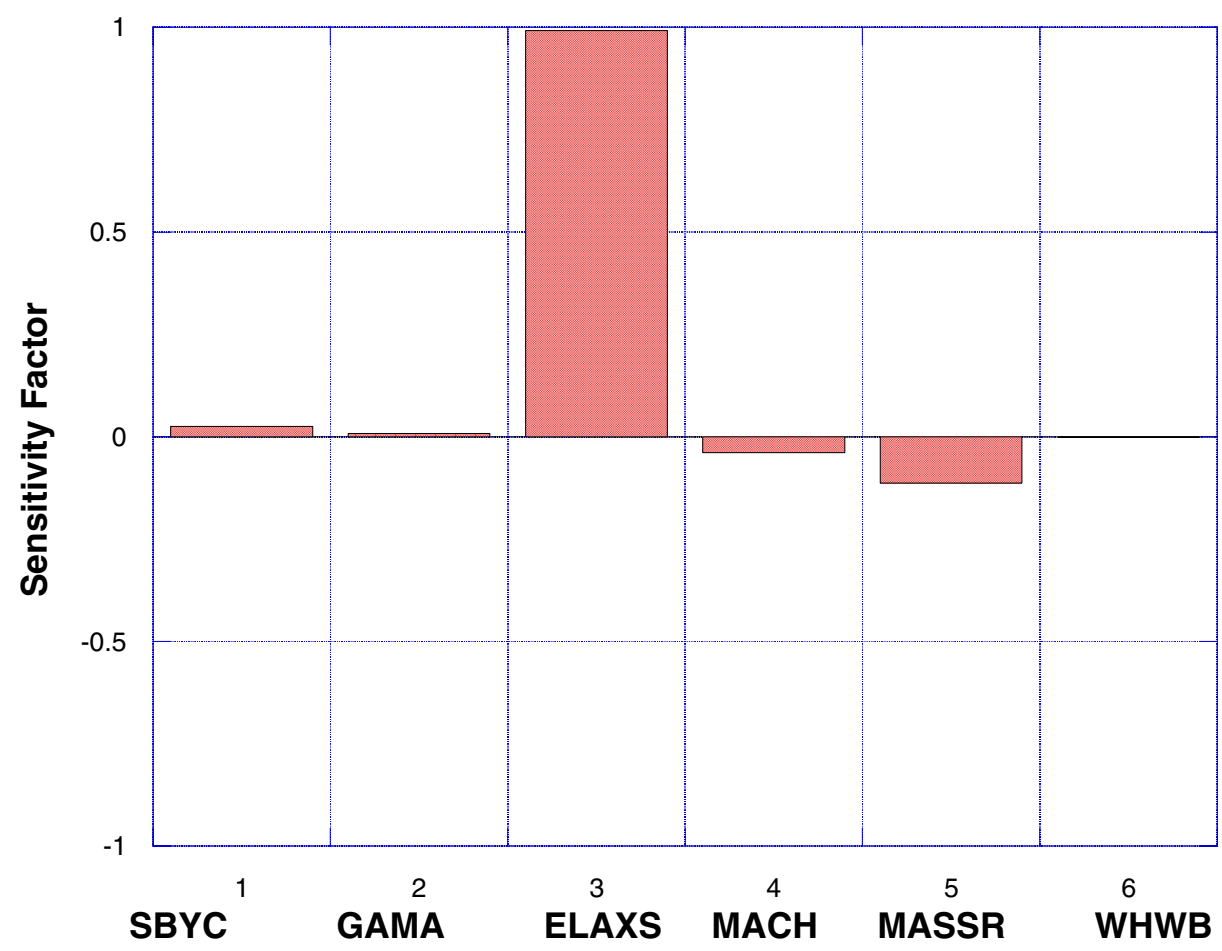

Figure 9.2.- Sensitivity factors of frequency (prob. level 0.999).

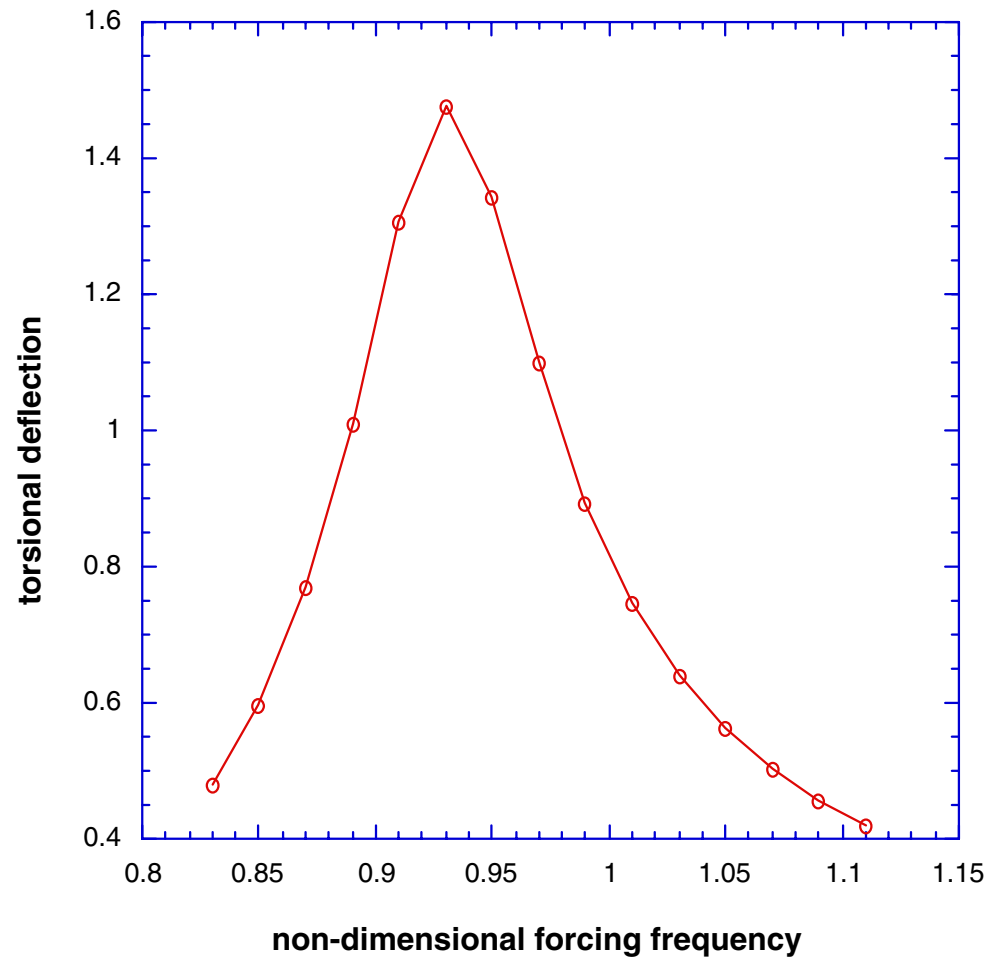

Figure 10.-Forced response of a 12 bladed cascade for vortical gust, $k_{b}=0.5, N=12, M=0.7$, torsion mode, structural damping ratio $=0.002$. 


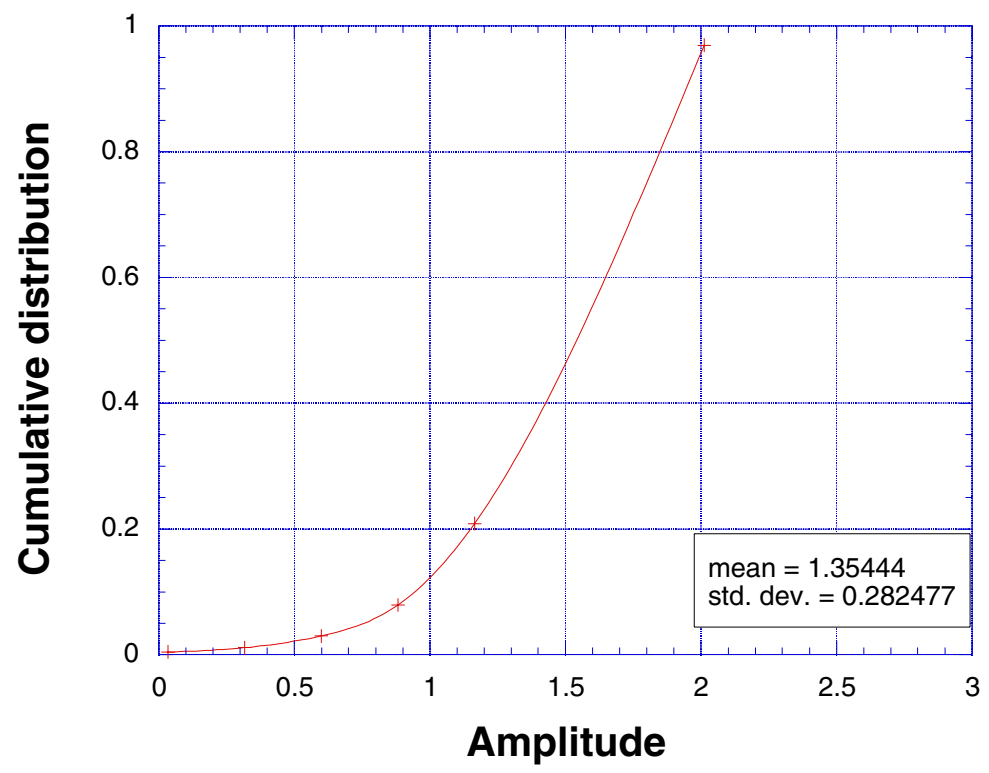

Figure 11.1.-Cumulative distribution function of torsional response amplitiude $\left(k_{b}=0.3\right)$.

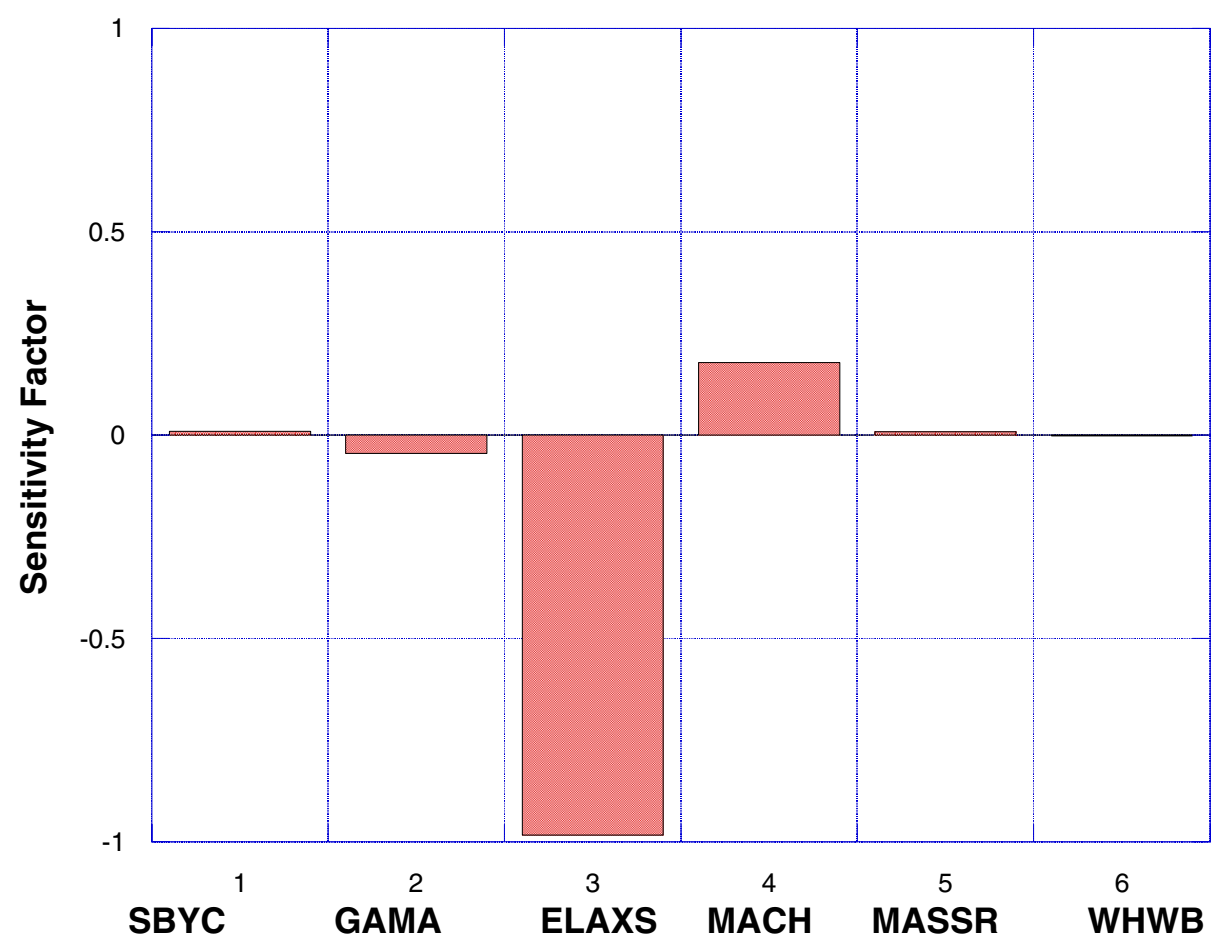

Figure 11.2.- Sensitivity factors of amplitude (prob. level 0.005). 


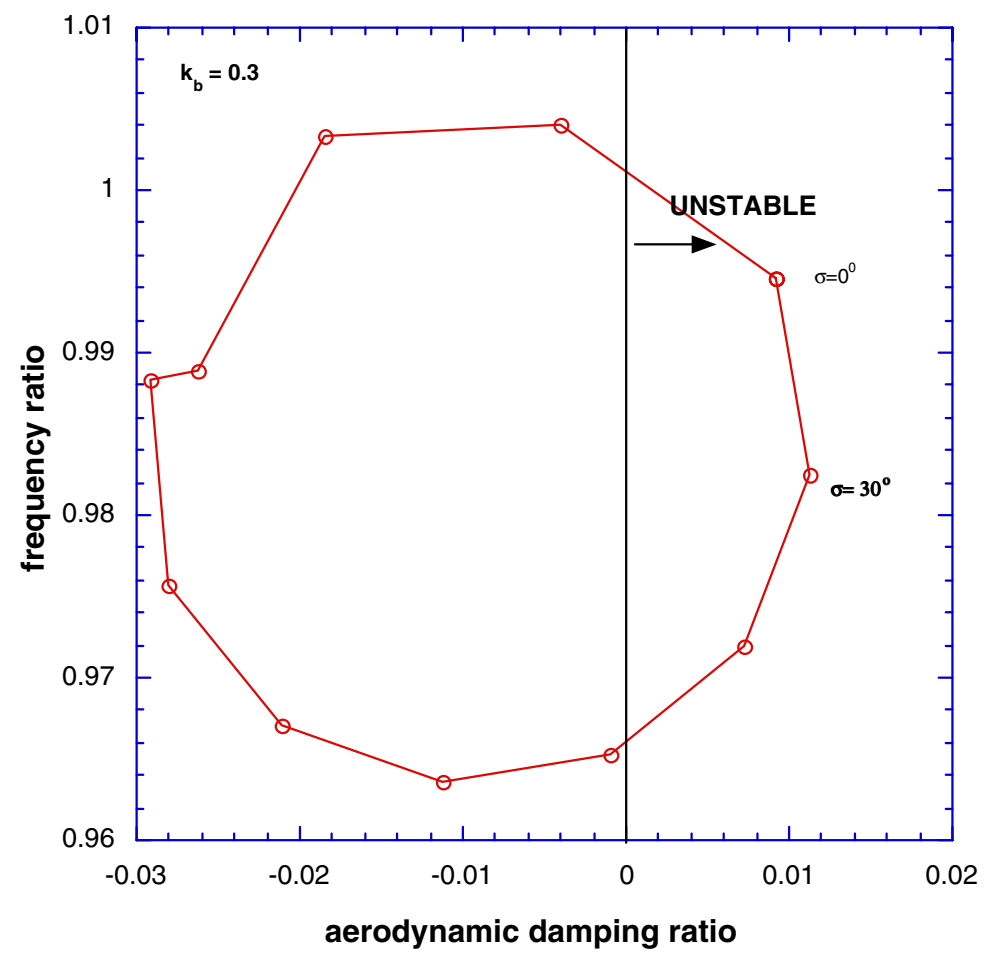

Figure 12.- Root locus plot for a 12 bladed cascade, Supersonic flow with subsonic leading edge, $N=12, M=1.2$, torsion mode, structural damping ratio $=0.0$.

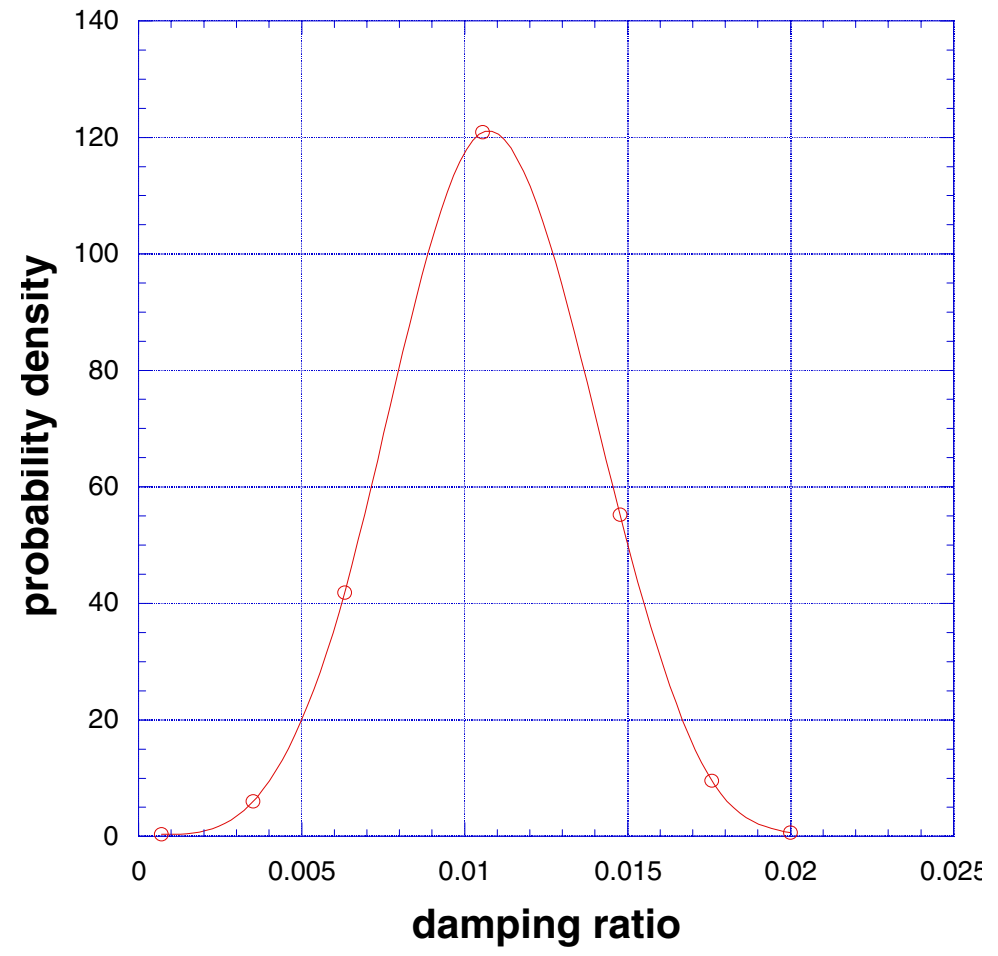

Figure 13.1.- Probability density function of damping $\left(k_{b}=0.3\right.$, torsion mode) 


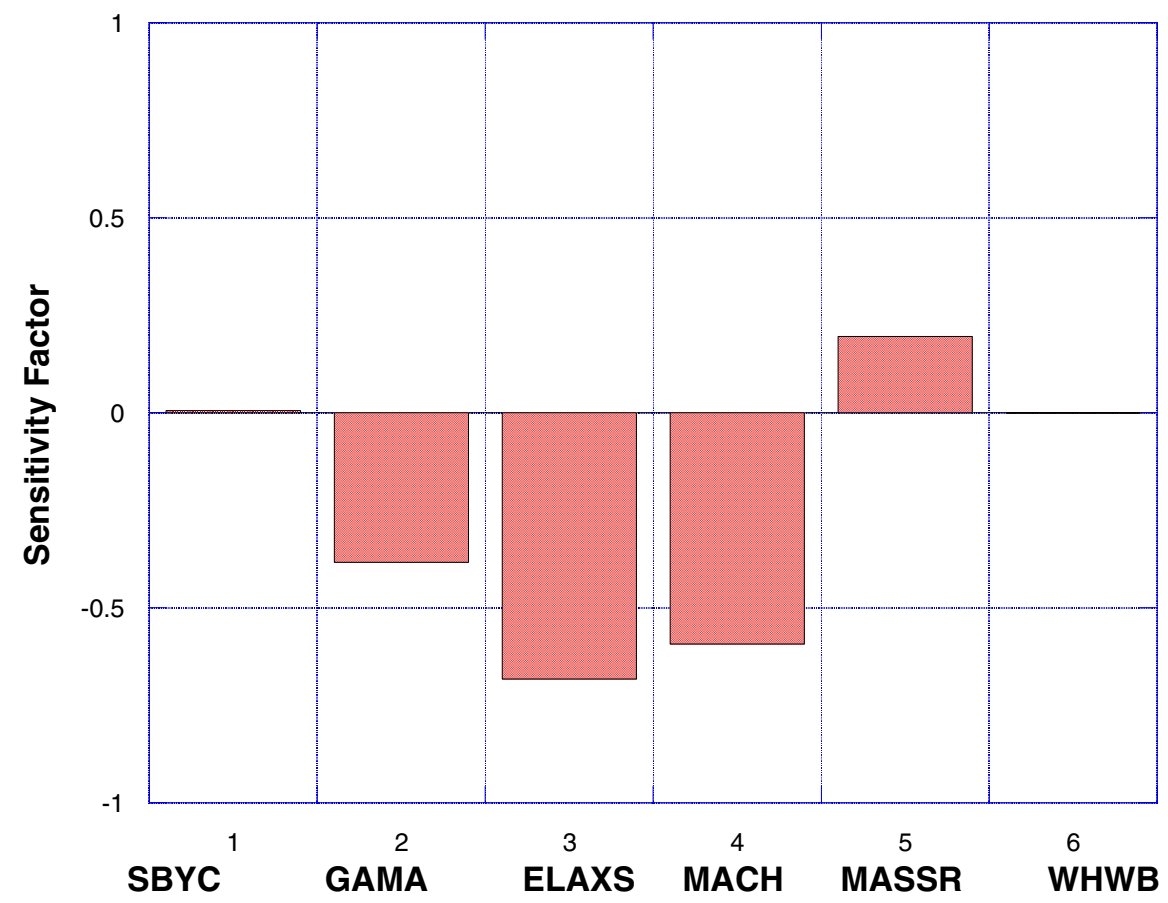

Figure 13.2.- Sensitivity factors of damping $\left(k_{b}=0.3\right.$, torsion mode $)$

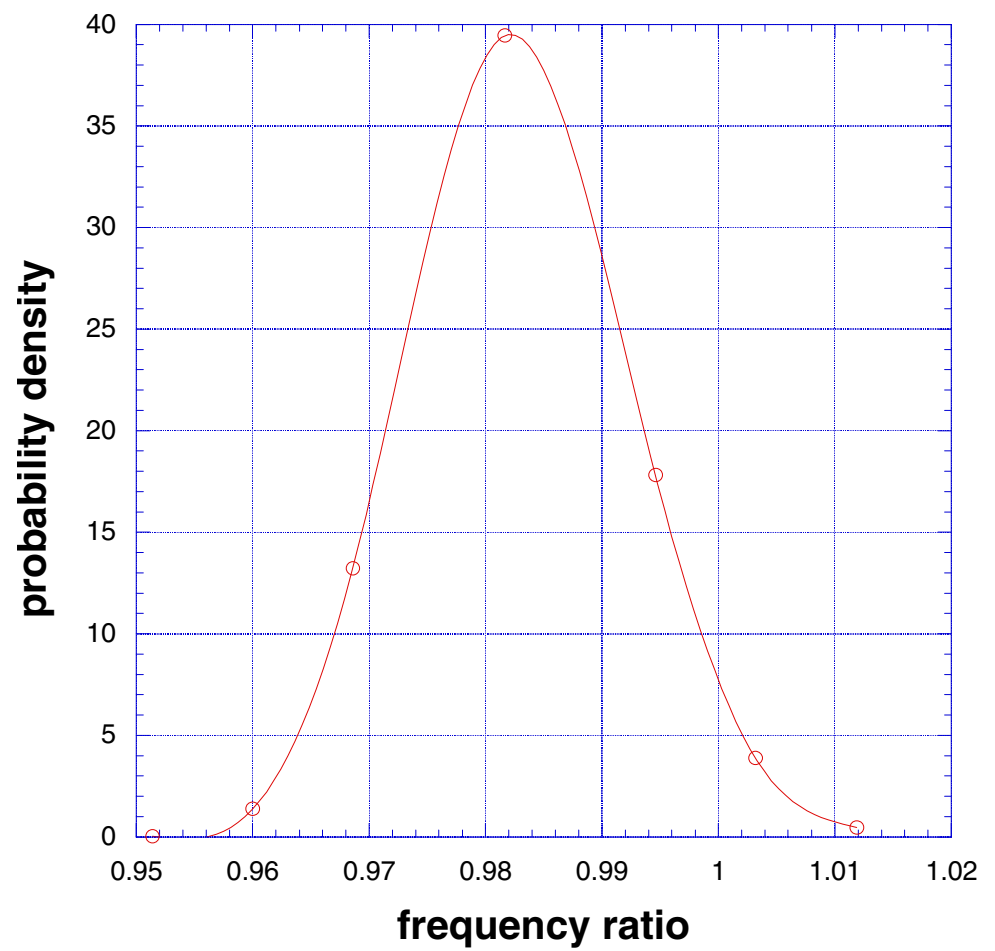

Figure 14.1.-Probability density function of frequency $\left(k_{b}=0.3\right.$, torsion mode). 


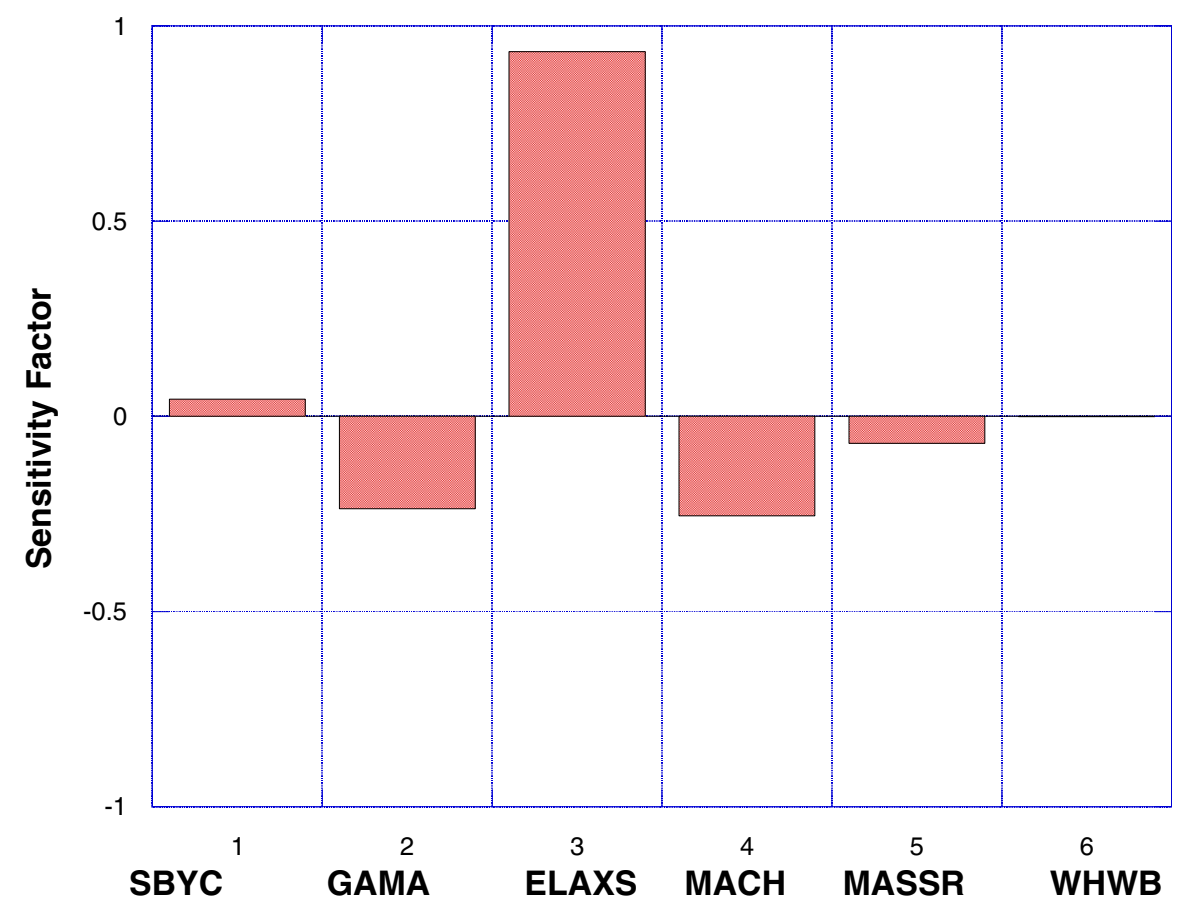

Figure 14.2.- Sensitivity factors of frequency $\left(k_{b}=0.3\right.$, torsion mode). 
Public reporting burden for this collection of information is estimated to average 1 hour per response, including the time for reviewing instructions, searching existing data sources, gathering and maintaining the data needed, and completing and reviewing the collection of information. Send comments regarding this burden estimate or any other aspect of this collection of information, including suggestions for reducing this burden, to Washington Headquarters Services, Directorate for Information Operations and Reports, 1215 Jefferson Davis Highway, Suite 1204, Arlington, VA 22202-4302, and to the Office of Management and Budget, Paperwork Reduction Project (0704-0188), Washington, DC 20503.

\begin{tabular}{|l|l|l}
\hline 1. AGENCY USE ONLY (Leave blank) & $\begin{array}{c}\text { 2. REPORT DATE } \\
\text { May } 2004\end{array}$ & $\begin{array}{c}\text { 3. REPORT TYPE AND DATES COVERED } \\
\text { Technical Memorandum }\end{array}$ \\
\hline
\end{tabular}

4. TITLE AND SUBTITLE

5. FUNDING NUMBERS

Probabilistic Aeroelastic Analysis of Turbomachinery Components

6. AUTHOR(S)

WBS-22-781-30-10

T.S.R. Reddy, S.K. Mital, and G.L. Stefko

7. PERFORMING ORGANIZATION NAME(S) AND ADDRESS(ES)

National Aeronautics and Space Administration

John H. Glenn Research Center at Lewis Field

Cleveland, Ohio 44135-3191

8. PERFORMING ORGANIZATION

REPORT NUMBER

E-14528

9. SPONSORING/MONITORING AGENCY NAME(S) AND ADDRESS(ES)

10. SPONSORING/MONITORING

AGENCY REPORT NUMBER

National Aeronautics and Space Administration

Washington, DC 20546-0001

NASA TM-2004-213063

11. SUPPLEMENTARY NOTES

T.S.R. Reddy and S.K. Mital, University of Toledo, Toledo, Ohio 43606-3390 and NASA Resident Research Associates at Glenn Research Center; and G.L. Stefko, NASA Glenn Research Center. Responsible person, George L. Stefko, organization code 5930, 216-433-3920.

12a. DISTRIBUTION/AVAILABILITY STATEMENT

12b. DISTRIBUTION CODE

Unclassified - Unlimited

Subject Category: 39

Distribution: Nonstandard

Available electronically at http://gltrs.grc.nasa.gov

This publication is available from the NASA Center for AeroSpace Information, 301-621-0390.

13. ABSTRACT (Maximum 200 words)

A probabilistic approach is described for aeroelastic analysis of turbomachinery blade rows. Blade rows with subsonic flow and blade rows with supersonic flow with subsonic leading edge are considered. To demonstrate the probabilistic approach, the flutter frequency, damping and forced response of a blade row representing a compressor geometry is considered. The analysis accounts for uncertainties in structural and aerodynamic design variables. The results are presented in the form of probabilistic density function (PDF) and sensitivity factors. For subsonic flow cascade, comparisons are also made with different probabilistic distributions, probabilistic methods, and Monte-Carlo simulation. The approach shows that the probabilistic approach provides a more realistic and systematic way to assess the effect of uncertainties in design variables on the aeroelastic instabilities and response.

14. SUBJECT TERMS

Aeroelasticity; Probabilistic analysis; Cascades; FPI

\begin{tabular}{|c|c|}
\hline $\begin{array}{c}\text { 17. SECURITY CLASSIFICATION } \\
\text { OF REPORT } \\
\text { Unclassified }\end{array}$ & $\begin{array}{c}\text { 18. SECURITY CLASSIFICATION } \\
\text { OF THIS PAGE } \\
\text { Unclassified }\end{array}$ \\
\hline
\end{tabular}

NSN 7540-01-280-5500

\begin{tabular}{|l|l|}
\hline & $\begin{array}{c}15 . \text { NUMBER OF PAGES } \\
27\end{array}$ \\
\cline { 2 - 2 } & 16. PRICE CODE \\
\hline $\begin{array}{c}\text { 19. SECURITY CLASSIFICATION } \\
\text { OF ABSTRACT } \\
\text { Unclassified }\end{array}$ & 20. LIMITATION OF ABSTRACT \\
\hline
\end{tabular}

Standard Form 298 (Rev. 2-89)

Prescribed by ANSI Std. Z39-18 298-102 

